\title{
Stability-Indicating HPLC Method for the Simultaneous Determination of HIV Tablet Containing Emtricitabine, Tenofovir Disoproxil Fumarate, and Rilpivirine Hydrochloride in Pharmaceutical Dosage Forms
}

\author{
S. Venkatesan, N. Kannappan, and Sai Sandeep Mannemala \\ Department of Pharmacy, Annamalai University, Chidambaram, Tamil Nadu 608002, India \\ Correspondence should be addressed to S. Venkatesan; venkatmpharm@rediffmail.com
}

Received 14 May 2014; Revised 18 August 2014; Accepted 20 August 2014; Published 29 October 2014

Academic Editor: Josep Esteve-Romero

Copyright (C) 2014 S. Venkatesan et al. This is an open access article distributed under the Creative Commons Attribution License, which permits unrestricted use, distribution, and reproduction in any medium, provided the original work is properly cited.

\begin{abstract}
A simple, accurate, rapid, and stability-indicating RP-HPLC method for a combination of tenofovir disoproxil fumarate, emtricitabine, and rilpivirine has been developed and subsequently validated in commercial tablets. The proposed HPLC method utilizes Phenomenex Gemini C18 column $(150 \mathrm{~mm} \times 4.6 \mathrm{~mm}$ i.d., $5 \mu \mathrm{m})$ and mobile phase consisting of MeCN, potassium dihydrogen phosphate buffer (20 mM, pH 3.3), and triethylamine 58.72: 41.23: 0.05 (v/v) at a flow rate of 1.7 mL/min. Quantitation was achieved with UV detection at $270 \mathrm{~nm}$. The method was validated in terms of accuracy, precision, linearity, limits of detection, limits of quantitation, and robustness. This optimized method has been successively applied to pharmaceutical formulation and no interference from the tablet excipients was found. TDF, EMT, and RPV and their combination drug product were subjected to acid, base, neutral hydrolysis, oxidation, dry heat, and photolytic stress conditions and the stressed samples were analyzed by the proposed method. As the proposed LC method could effectively separate the drugs from its degradation products, it can be employed as stability-indicating method for the determination of instability of these drugs in bulk and commercial tablets.
\end{abstract}

\section{Introduction}

Safety and efficacy of pharmaceuticals are two basic problems with importance in drug therapy. Instability of pharmaceuticals can cause a change in physical, chemical, pharmacologi$\mathrm{cal}$, and toxicological properties of the active pharmaceutical ingredients (API), thereby affecting its safety and efficacy. Hence, the pharmacists should take cognizance of various factors such as drug stability, possible degradation products, mechanisms and routes of degradation, and potential interactions with excipients utilized in the formulation to ensure the delivery of their therapeutic values to patients. In order to assess the stability of a drug product, one needs an appropriate analytical methodology, the so-called stability-indicating methods which allow accurate and precise quantitation of the drug and its degradation products and interaction products, if any. In recent times, the development of stabilityindicating assays has increased dramatically using the approach of stress testing as enshrined in ICH guideline [1] and even this approach is being extended to drug combinations. This ICH guideline requires that stress testing on API and drug products should be carried out to establish their inherent stability characteristics, which should include the effect of temperature, humidity, light, and oxidizing agents as well as susceptibility across a wide range of $\mathrm{pH}$. However, there are no detailed regulatory guidelines that direct how stress testing is to be done and hence stress testing has evolved into an "artful science" that is highly dependent on the experience of the pharmaceutical industries or the individuals directing the studies.

EMT, a synthetic nucleoside analog of cytidine, is phosphorylated by cellular enzymes to form EMT $5^{\prime}$-triphosphate. EMT $5^{\prime}$-triphosphate inhibits the activity of the HIV-1 RT by competing with the natural substrate deoxycytidine $5^{\prime}$ triphosphate and by being incorporated into nascent viral DNA which results in chain termination. 
<smiles>C[C@H](Cn1cnc2c(N)ncnc21)OCP(=O)(O)O</smiles>

(a) Tenofovir<smiles>Nc1nc(=O)n([C@H]2CS[C@@H](CO)O2)cc1F</smiles>

(b) Emtricitabine

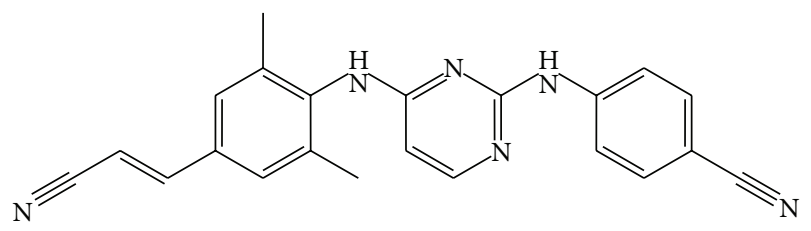

(c) Rilpivirine

Figure 1: Chemical structure of analytes: (a) tenofovir, (b) emtricitabine, and (c) rilpivirine.

TDF is an orally bioavailable ester prodrug of tenofovir (also known as PMPA), an acyclic nucleotide analog with activity in vitro against retroviruses, including HIV-1, HIV2 , and hepatitis $\mathrm{B}$ virus (HBV). Due to the presence of a phosphonate group, TDF is negatively charged at neutral $\mathrm{pH}$, which limits its oral bioavailability. Following absorption, TDF is rapidly converted to tenofovir which is metabolized intracellularly to the active metabolite, TDF diphosphate, a competitive inhibitor of HIV-1 RT that terminates the growing DNA chain. Acyclic phosphono-methyl ether nucleosides like TDF exhibit distinct biological properties. Due to their efficient intracellular activation to their active metabolites, they possess potent antiviral activity in vivo [2].

$\mathrm{RPV}$ is a second generation nonnucleoside reverse transcriptase inhibitor (NNRTI) for the treatment of HIV. It has higher potency, longer half-life, and reduced side-effect profile compared with older NNRTIs such as efavirenz. It has demonstrated activity against NNRTI resistant viral strains due to the flexibility of interactions with the HIV RT [3].

Highly active antiretroviral therapy (HAART) has brought new hope for those people who live with HIV/AIDS by decreasing the morbidity and mortality among people infected with HIV. Highly active antiretroviral therapy also has improved the quality of life among the people who live with HIV/AIDS [4]. The fixed dose combinations of nucleoside RT inhibitors EMT, TDF, and NNRTI RPV (Figure 1) are effective in the therapy of human immunodeficiency virus infection. It is used as a part of highly active antiretroviral therapy for the treatment of HIV. Three drug fixed dose combinations (FDCs) comprising EMT, TDF, and RPV form one of the first line regimens in HIV-therapy $[5,6]$.
Literature indicates that spectrophotometry [7-11], HPLC [12-15], HPTLC [16], and LC/MS/MS [17] methods for determination of TDF individually and in combination with other drugs in pharmaceutical formulations have been reported for drug substance and biological matrices.

Similarly, for EMT individually and in combination with other drugs by UV [18], HPLC in pharmaceutical formulations, drug substance, and biological matrices [19-21], LC/MS/MS [22], and stability-indicating liquid chromatographic methods [23] were reported.

A detailed literature survey for RPV revealed that few analytical methods are available using Spectrophotometry [24], HPLC [25] and HPTLC [26] were reported individually. However, an intensive literature search revealed to the best of our knowledge that only two methods are available for the determination of these analytes, EMT, TDF, and RPV, in pharmaceutical mixtures $[27,28]$.

Hence, recently, we have developed an optimized reversed-phase HPLC method for the routine quality control analysis of EMT, TDF, and RPV simultaneously from tablets. The method gave acceptable results for fresh quality control samples but gave overestimation during analysis of stability samples and aged products, as it lacks assay specificity in the presence of their degradation products. Further, no stabilityindicating method has been reported in literature for simultaneous determination of EMT, TDF, and RPV in presence of their degradants.

Therefore, the present study targets the development and subsequent validation of a stability-indicating assay of new RP-HPLC method for the simultaneous determination of EMT, TDF, and RPV in presence of interaction/degradation product.

\section{Material and Methods}

\subsection{Experimental}

2.1.1. Materials. Analytical pure samples of emtricitabine (C.C. Lab, Torrent Pharmaceutical Ltd., Indrad, India), tenofovir disoproxil fumarate (Sequent Research Lab., Mangalore, India), and rilpivirine (USV Ltd., Himachal Pradesh, India) were used in this study. The pharmaceutical dosage form used in this study was Complera procured from the local market and labelled to contain $200 \mathrm{mg}$ of emtricitabine, $300 \mathrm{mg}$ of tenofovir disoproxil fumarate, and $25 \mathrm{mg}$ of rilpivirine per tablet. The solvent of acetonitrile (MeCN) was of HPLC grade and potassium dihydrogen phosphate, sodium hydroxide, hydrochloric acid, hydrogen peroxide, and triethylamine were of analytical reagent grade purchased from Merck, India. The HPLC grade water was prepared by using Milli-Q Academic, Millipore, Bangalore, India.

2.1.2. Instrumentation. The LC system of Shimadzu model with UV-visible detector (SPD-10A) was used for this study and chromatographic separation was achieved on Phenomenex C18 $(150 \mathrm{~mm} \times 4.6 \mathrm{~mm}$ i.d., $5 \mu \mathrm{m})$ column as stationary phase with isocratic mode.

2.1.3. Chromatographic Condition. Chromatographic separations were carried out on a Phenomenex C18 analytical 
column $(150 \mathrm{~mm} \times 4.6 \mathrm{~mm}$ i.d., $5 \mu \mathrm{m})$ connected with a Phenomenex $\mathrm{C} 18$ guard cartridge $(4 \mathrm{~mm} \times 3 \mathrm{~mm}$ i.d., $5 \mu \mathrm{m})$. The mobile phase consisted of $\mathrm{MeCN}$ - potassium dihydrogen phosphate buffer (20 mM, pH 3.3)-and triethylamine. Wavelength of $270 \mathrm{~nm}$ was selected for detection. The injection volume of the sample was $20 \mu \mathrm{L}$. The HPLC system was used in an air-conditioned laboratory atmosphere.

2.1.4. Standard Solutions. Stock solutions of EMT, TDF, and RPV were prepared in mobile phase. Working standard solutions were freshly obtained by diluting the stock standard solutions with mobile phase during the day of analysis. The standard solution prepared for the optimization procedure constituted EMT, TDF, and RPV at 56.0, 84.0, and $7.0 \mu \mathrm{g} / \mathrm{mL}$, respectively.

2.1.5. Sample Preparation. Twenty tablets were weighed and finely powdered. An amount of tablet powder equivalent to $20 \mathrm{mg}$ of EMT and $30 \mathrm{mg}$ of TDF with $2.5 \mathrm{mg}$ of RPV was accurately weighed and transferred into a $50 \mathrm{~mL}$ volumetric flask. This mixture was subjected to sonication for $10 \mathrm{~min}$ for complete extraction of drugs. From the above solution, $7 \mathrm{~mL}$ of solution was pipetted out into $50 \mathrm{~mL}$ volumetric flask; the solution was made up to the mark with a mobile phase to obtain concentrations of $56.0,84.0$, and $7.0 \mu \mathrm{g} / \mathrm{mL}$ of EMT, TDF, and RPV, respectively, for stability-indicating assay tablets.

2.1.6. Forced Degradation Studies of API and Tablets. The marketed Complera tablets containing $200 \mathrm{mg}$ of EMT, $300 \mathrm{mg}$ of TDF, and $25 \mathrm{mg}$ of RPV were subjected to various forced degradation conditions to effect partial degradation of the drug preferably in $2-30 \%$ range $[29,30]$. The forced degradation studies were performed not only for the drug product, but also for API of EMT, TDF, and RPV to determine whether any observed degradation occurred because of drug properties or drug-excipient interactions. Moreover, the studies provide information about the conditions in which the drug is unstable so that measures can be taken during formulation to avoid potential instabilities. The stability samples were prepared by dissolving each API or drug product in mobile phase and later diluted with either distilled water, aqueous hydrochloric acid, aqueous sodium hydroxide, or aqueous hydrogen peroxide solution at concentrations of 400 (EMT), 600 (TDF), and 50 (RPV) $\mu \mathrm{g} / \mathrm{mL}$ separately. After the degradation treatments were completed, the stress content solutions were allowed to equilibrate to room temperature and dilute with mobile phase to achieve the nominal concentrations of 56 (EMT), 84 (TDF), and 7 (RPV) $\mu \mathrm{g} / \mathrm{mL}$, which was based on their label strength in tablets.

2.1.7. Acid Hydrolysis. Solutions for acid degradation studies were prepared in mobile phase and $0.3 \mathrm{~N}$ hydrochloric acid at room temperature for $24 \mathrm{hrs}$ and mixture was neutralized and the resultant solutions were analyzed after 5-10 min of preparation.
2.1.8. Base Hydrolysis. Solutions for base degradation studies were prepared in mobile phase and $0.1 \mathrm{~N}$ sodium hydroxide at room temperature for $2 \mathrm{hrs}$ and mixture was neutralized and the resultant solutions were analyzed after 5-10 min of preparation.

2.1.9. Neutral Hydrolysis. Solutions for neutral degradation studies were prepared in mobile phase and water and the resultant solutions heated on a water bath at $90^{\circ} \mathrm{C}$ for $20 \mathrm{~min}$. The mixture was neutralized and then allowed to cool at room temperature, filtered using syringe filters, and analyzed after 5-10 min of preparation.

2.1.10. Oxidation Studies. Solutions for use in oxidation studies were prepared in mobile phase and $8 \%$ hydrogen peroxide at room temperature for $5 \mathrm{hrs}$ and the resultant solutions were filtered using syringe filters and analyzed after 5-10 min.

2.1.11. Photostability Studies. Solutions for photostability studies were prepared in mobile phase and the resultant solution was exposed to natural sunlight during the day time for $8 \mathrm{hrs}$ for 3 days. The degraded sample was then filtered using syringe filters and analyzed.

2.1.12. Temperature Stress Studies. Tablets and API in powder forms were exposed to dry heat $\left(60^{\circ} \mathrm{C}\right)$ in an oven for $24 \mathrm{hrs}$. The API and tablet powders were then removed from the oven and an aliquot of tablet powder equivalent to the weight of one tablet was prepared for analysis as previously described.

\section{Results and Discussion}

3.1. HPLC Method Development. Our earlier HPLC method was optimized with respect to mobile phase composition, buffer concentration, and flow rate to achieve an optimal chromatographic condition for the separation and simultaneous quantification of EMT, TDF, and RPV from Complera tablet containing EMT $200 \mathrm{mg}$, TDF $300 \mathrm{mg}$, and RPV $25 \mathrm{mg}$. This optimized method employs Phenomenex Gemini C18 column $(150 \mathrm{~mm} \times 4.6 \mathrm{~mm}$ i.d., $5 \mu \mathrm{m})$ and mobile phase consisting of $\mathrm{MeCN}$ - potassium dihydrogen phosphate buffer (20 mM, pH 3.3)—and triethylamine 58.72: $41.23: 0.05$ (v/v) for the separation of EMT, TDF, and RPV without affecting the stability of these analytes. However, this method does not give data on specificity for the estimation of the three analytes in the presence of their degradants. Therefore, as an attempt to develop stability-indicating assay, the same optimal chromatographic condition has been tried to separate these analytes from the degradation products generated during forced degradation studies. Using this customized optimized method, it was possible to separate EMT, TDF, and RPV and their degradation products without any interference and thus the assay can be considered stability-indicating.

3.2. Degradation Behavior. Preliminary trials on individual drugs and those in tablet dosage form were conducted to optimize various stress conditions. Samples were withdrawn at $3-5 \mathrm{hr}$ intervals to monitor the rate of degradation and 
optimize the stress conditions. Degradation conditions were attenuated such that all three drugs would get degraded in the range of $2-30 \%$ for establishing the stability-indicating nature of the assay method. Forced degradation studies of APIs of three analytes and formulations (Complera tablet) were carried out under various stress conditions.

The extents of degradation of the three analytes in Complera tablet are shown in Figure 2. The degradation product formed from each drug has been identified by comparing the respective chromatograms of each API with formulations obtained after forced degradation studies. Each of the degradation or interaction products was given the name with respect to its original source like $R_{1}$ : the degradation product of RPV.

Labeling of all degradation products was done by a degrading individual drug with a similar condition as used for the combination tablets. Retention time and wavelength of degradation product were useful parameters to label degradation products. Such labeling was very useful to identify common degradation products among different degradation conditions.

All three APIs and tablet showed no degradation in $0.1 \mathrm{~N}$ $\mathrm{HCl}$ at room temperature for 24 hours; therefore, drastic condition was experimented with the use of higher concentration of $\mathrm{HCl}$ and reflux. EMT and TDF were easily susceptible to degradation in comparison to RPV in drastic condition and TDF and EMT undergo 18\% and 16\% decomposition under acidic stress condition for both pure and tablet dosage form. Similarly, RPV undergoes 3\% decomposition under the same condition for both pure and tablet dosage form.

All drugs showed sufficient degradation when subjected to milder stress conditions of $0.1 \mathrm{~N} \mathrm{NaOH}$ at room temperature for 2 hours. TDF was comparatively more prone to degradation under basic conditions. TDF underwent complete degradation when higher stress conditions were used. TDF undergoes $31 \%$ decomposition under basic stress condition whereas EMT and RPV undergo 17\% and 7\% degradation for both pure and tablet dosage form. RPV was quite stable under neutral degradation due to its nonpolar nature whereas TDF and EMT undergo $11 \%$ and $7 \%$ degradation, respectively, for both APIs and tablet dosage forms.

In oxidation stress condition, lower concentration of oxidizing agent was insufficient to give sufficient degradation for RPV even after prolonged exposure. Hence, samples were stressed at harsher conditions of $8 \% \mathrm{H}_{2} \mathrm{O}_{2}$ at room temperature for 5 hrs. EMT, TDF, and RPV in APIs and tablets were moderately stable showing $12 \%, 13 \%$, and $7 \%$ degradation, respectively.

In photolytic degradation, APIs and tablets were exposed to direct sunlight at 8 hours for 3 days. EMT, TDF, and RPV in APIs and tablets were highly stable and they undergo degradations of $2 \%, 6 \%$, and $1 \%$, respectively. Similarly, in thermal degradation subjected to dry heat $\left(60^{\circ} \mathrm{C}\right)$ in an oven for 24 hours, EMT, TDF, and RPV in APIs and tablets were highly stable and they undergo degradations of $2 \%, 5 \%$, and $1 \%$, respectively. The degradation products of EMT, TDF, and RPV were found to be similar for all the formulations (Complera tablet) and API powders assessed.
The stability of stock solutions (stored at $2-8^{\circ} \mathrm{C}$ and at ambient temperature for 3 days) was determined by quantitation of each drug in solution in comparison to the response obtained for freshly prepared standard solutions. No significant changes $(<2 \%)$ were observed for the chromatographic responses for the stock solutions analyzed, relative to freshly prepared standards.

The degradation study was not intended to identify the degradation products but merely to show that they would not interfere if and when they present. To conclude, the results of stress testing studies indicate a high degree of specificity of this method for EMT, TDF, and RPV.

3.3. Method Validation Parameters. The optimized HPLC method for the analysis of fresh quality control samples was validated in accordance with the ICH Q2 (R1) [31] guidelines and reported.

3.4. Selection of Wavelength. The sensitivity of the HPLC method that uses UV detection depends upon the proper selection of the wavelength. The standard solutions were scanned from 200 to $400 \mathrm{~nm}$ and the overlain UV spectra obtained were recorded (Figure 3). From the overlain UV spectra, the detection wavelengths were selected for the methods to estimate simultaneously two or more drugs; the drugs in multicomponent dosage forms used in the present study gave good peak response at the wavelength selected.

3.5. Specificity. The results of forced degradation studies of each drug in the presence of their degradation products indicated a high degree of specificity of this method for EMT, TDF, and RPV. The degradation product of each of the parent peaks was found to be similar for the Complera tablet compared to that of API powders assessed. Typical chromatograms obtained following the assay of untreated and stressed samples of API and formulations are shown in Figure 2.

3.6. Accuracy. Accuracy of the method was determined by performing the recovery experiment at 50, 100, and $150 \%$ levels of the labeled number of the analytes in the commercial formulation. The recoveries for EMT, TDF, and RPV were found to be $99.50,99.90$, and $99 \%$, respectively, which were within acceptable ranges of $100 \pm 2 \%$. The results are presented in Table 1.

3.7. Precision. The $\% \mathrm{RSD}$ values for the intraday and interday precision were $\leq 2 \%$ confirming that the method was sufficiently precise. The results are presented in Table 2 .

3.8. Linearity and Range. The linearity was established over the ranges of 28-84, 42-126, and 3.5-10.5 for EMT, TDF, and $\mathrm{RPV}$, respectively. Correlation coefficients $\left(R^{2}\right)$ were found to be more than 0.999 for all the analytes. Typically, the means of the regression equations were $y=87545 x+15731, y=$ $41493 x+18505$, and $y=23045 x+65860$ for EMT, TDF, and RPV. The LOD and LOQ were estimated as 1.90 and 


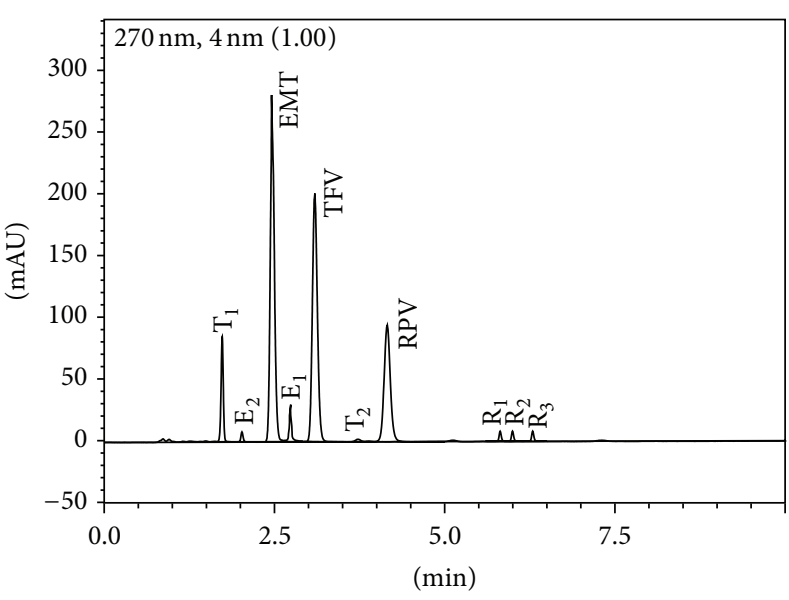

(a) Acid hydrolytic degradation

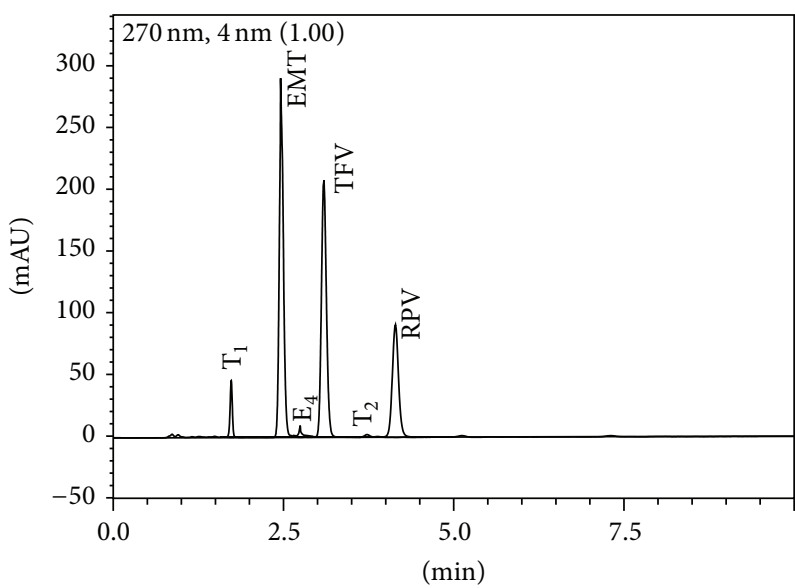

(c) Neutral hydrolytic degradation

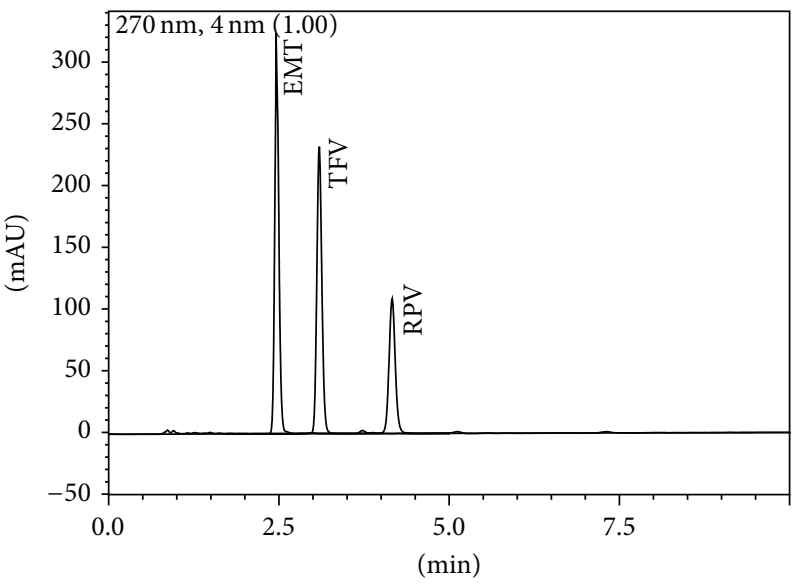

(e) Thermal degradation

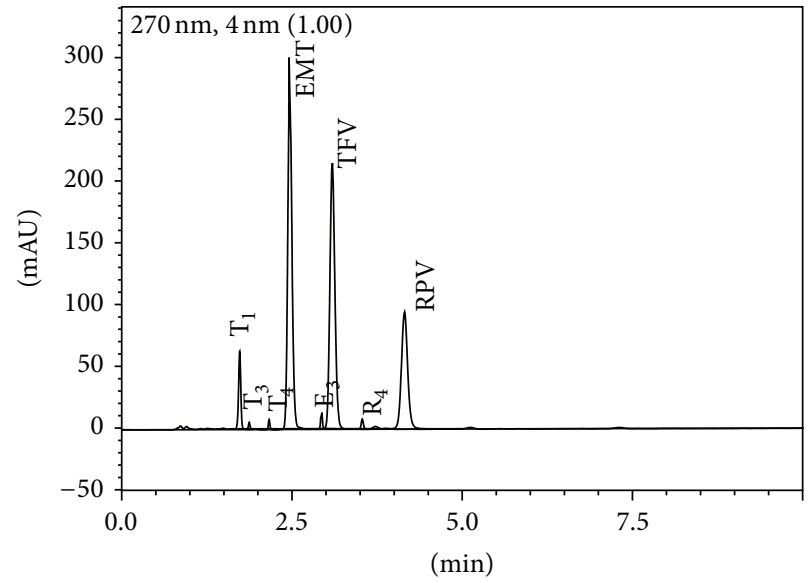

(b) Base hydrolytic degradation

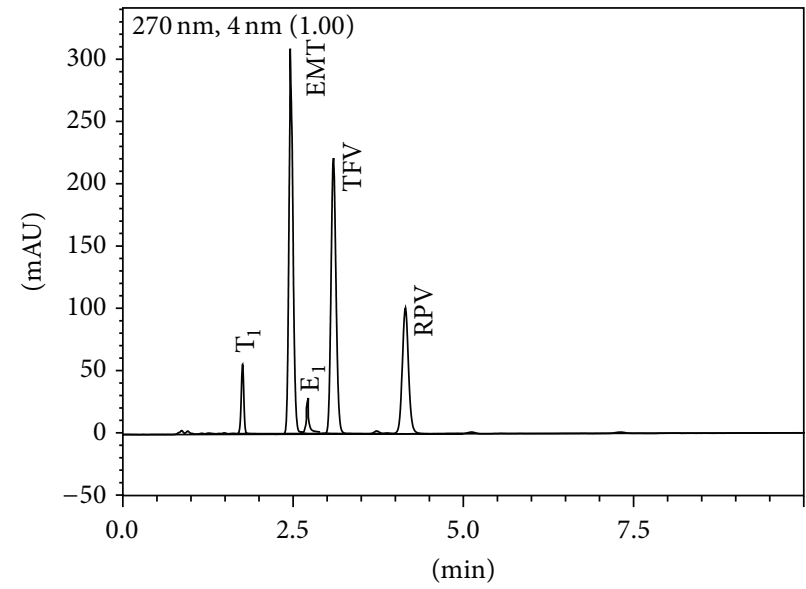

(d) Oxidation degradation

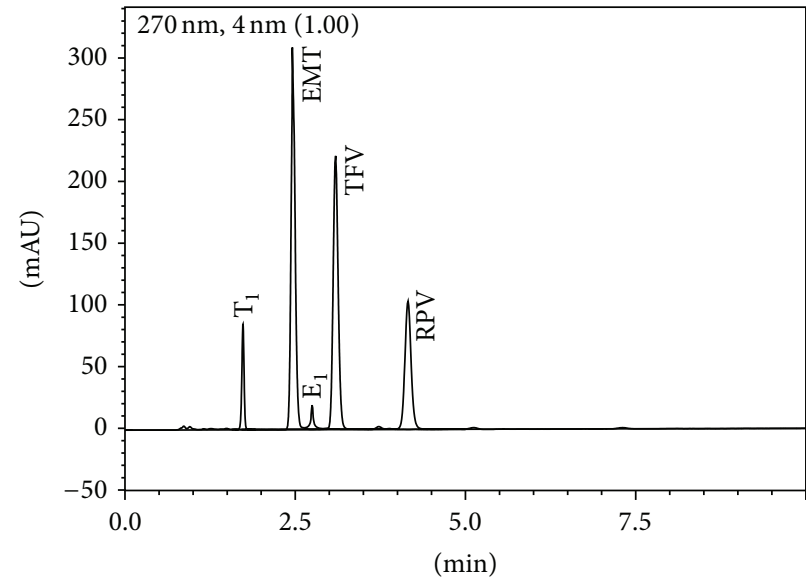

(f) Photolytic degradation

FIGURE 2: HPLC chromatographic separation of TDF, EMT, and RPV and its degradation product in different stress conditions.[The labeling of degradation products from its original source. For instance, emtricitabine $\left(\mathrm{E}_{1} \mathrm{E}_{2} \& \mathrm{E}_{3}\right)$, tenofovir $\left(\mathrm{T}_{1} \mathrm{~T}_{2} \& \mathrm{~T}_{3}\right)$ and rilpivirine $\left(\mathrm{R}_{1} \mathrm{R}_{2} \&\right.$ $\left.\mathrm{R}_{3}\right)$ ]. 
TABLE 1: Recovery studies for EMT, TDF, and RPV.

\begin{tabular}{lccccccccc}
\hline \multirow{2}{*}{ Con. (\%) } & \multicolumn{3}{c}{ Added amount (mg) } & \multicolumn{3}{c}{ Amount recovered (mg) } & \multicolumn{3}{c}{ Percentage recovered (\%) } \\
& EMT & TDF & RPV & EMT & TDF & RPV & EMT & TDF & RPV \\
\hline 50 & 10 & 15 & 1.25 & 9.953 & 14.98 & 1.23 & 99.53 & 99.92 & 99.14 \\
100 & 20 & 30 & 2.5 & 19.90 & 29.95 & 2.47 & 99.52 & 99.83 \\
150 & 30 & 45 & 3.75 & 29.83 & 44.97 & 3.70 & 99.45 & 99.95 & 98.04 \\
\hline \multicolumn{4}{c}{ Mean \% recovery $(n=9)$} & & & 99.50 & 99.90 & 99.00 \\
& \multicolumn{4}{c}{ \%RSD } & & & 0.044 & 0.104 & 0.061 \\
\hline
\end{tabular}

TABle 2: Precision results for EMT, TDF, and RPV.

\begin{tabular}{|c|c|c|c|c|c|c|c|c|c|c|}
\hline \multirow[b]{2}{*}{ Parameter } & \multirow[b]{2}{*}{ Sampling interval } & \multicolumn{3}{|c|}{ EMT } & \multicolumn{3}{|c|}{ TDF } & \multicolumn{3}{|c|}{ RPV } \\
\hline & & $\begin{array}{c}\text { Amount present } \\
(\mathrm{mg})\end{array}$ & $(\%)$ & $\% \mathrm{RSD}$ & $\begin{array}{c}\text { Amount present } \\
(\mathrm{mg})\end{array}$ & $(\%)$ & $\% \mathrm{RSD}$ & $\begin{array}{c}\text { Amount present } \\
(\mathrm{mg})\end{array}$ & $(\%)$ & $\%$ RSD \\
\hline \multirow{3}{*}{ Within-day } & $0 \mathrm{hrs}$ & 200.77 & 100.38 & 0.252 & 299.72 & 99.90 & 0.355 & 24.42 & 97.70 & 1.592 \\
\hline & $8 \mathrm{hrs}$ & 198.69 & 99.34 & 0.100 & 299.48 & 99.82 & 0.487 & 24.74 & 98.99 & 0.181 \\
\hline & $16 \mathrm{hrs}$ & 198.37 & 99.18 & 0.021 & 299.78 & 99.92 & 0.026 & 24.75 & 99.03 & 0.442 \\
\hline \multirow{3}{*}{ Between days } & 1st day & 198.94 & 99.47 & 0.063 & 299.68 & 99.89 & 0.025 & 24.91 & 99.64 & 0.136 \\
\hline & 2nd day & 198.60 & 99.30 & 0.047 & 299.54 & 99.84 & 0.011 & 24.73 & 98.93 & 0.207 \\
\hline & 3rd day & 197.66 & 98.83 & 0.025 & 298.94 & 99.64 & 0.107 & 24.57 & 98.31 & 0.643 \\
\hline
\end{tabular}

TABLE 3: Evaluation data of robustness study.

\begin{tabular}{|c|c|c|c|c|c|c|c|c|c|c|}
\hline \multirow[b]{2}{*}{ Parameter } & \multirow[b]{2}{*}{ Sampling interval } & \multicolumn{3}{|c|}{ EMT } & \multicolumn{3}{|c|}{ TDF } & \multicolumn{3}{|c|}{ RPV } \\
\hline & & $\begin{array}{c}\text { Amount present } \\
(\mathrm{mg})\end{array}$ & $(\%)$ & $\% \mathrm{RSD}$ & $\begin{array}{c}\text { Amount present } \\
(\mathrm{mg})\end{array}$ & $(\%)$ & $\% \mathrm{RSD}$ & $\begin{array}{c}\text { Amount present } \\
(\mathrm{mg})\end{array}$ & $(\%)$ & $\% \mathrm{RSD}$ \\
\hline \multirow{2}{*}{ Wavelength } & $-1 \mathrm{~nm}$ & 200.25 & 100.12 & 0.334 & 297.04 & 99.01 & 0.837 & 24.63 & 98.54 & 0.001 \\
\hline & $+1 \mathrm{~nm}$ & 200.10 & 100.50 & 0.624 & 299.47 & 99.82 & 0.323 & 24.92 & 99.68 & 0.029 \\
\hline \multirow{2}{*}{ Mobile phase } & $-2 \%$ & 200.16 & 100.08 & 0.225 & 299.44 & 99.81 & 0.163 & 24.82 & 99.30 & 0.689 \\
\hline & $+2 \%$ & 200.09 & 100.04 & 0.430 & 298.92 & 99.64 & 0.509 & 24.68 & 98.75 & 0.370 \\
\hline \multirow{2}{*}{ Flow rate } & $-0.1 \mathrm{~mL}$ & 198.81 & 99.40 & 0.837 & 300.55 & 100.18 & 0.019 & 24.47 & 97.89 & 1.469 \\
\hline & $+0.1 \mathrm{~mL}$ & 196.28 & 98.14 & 3.192 & 298.49 & 99.49 & 0.403 & 24.68 & 98.74 & 0.378 \\
\hline \multirow{2}{*}{$\mathrm{pH}$} & -0.05 & 199.7 & 99.85 & 0.74 & 298.7 & 99.56 & 0.21 & 24.59 & 98.36 & 0.22 \\
\hline & +0.05 & 199.9 & 99.95 & 0.63 & 300.4 & 100.1 & 0.11 & 24.71 & 98.84 & 0.34 \\
\hline
\end{tabular}

$0.43 \mathrm{ng} / \mathrm{mL}$ for EMT, 2.18 and $0.54 \mathrm{ng} / \mathrm{mL}$ for TDF, and 3.12 and $1.78 \mathrm{ng} / \mathrm{mL}$ for RPV.

3.9. Robustness Test. Robustness of the method was checked by small deliberate changes made in the method parameters such as wavelength $( \pm 2 \mathrm{~nm})$, mobile phase ratio $( \pm 2 \%)$, flow rate $( \pm 0.1 \mathrm{~mL})$, and $\mathrm{pH}( \pm 0.05)$, but these changes did not affect the method results. The $\%$ RSD for the tablets were $<2$, indicating the robustness of the analytical methodology. The results are presented in Table 3.

3.10. Ruggedness. A study was conducted to determine the effect of variation in analyst to analyst, lab to lab, and instrument to instrument in triplicate measurement as per the assay method. \%RSD was calculated for each condition and results are presented in Table 4.

3.11. Solution Stability Study. Table 5 shows the results obtained in the solution stability study at different time intervals for test preparation. It was concluded that the test preparation solution was found stable up to $72 \mathrm{~h}$ at $2-8^{\circ} \mathrm{C}$ and was at ambient temperature as during this time the result was not decreased below the minimum percentage.

3.12. Application of the Method. The optimized and validated formulation assay method was applied to the quantitative analysis of commercial tablet (Complera) and was evaluated by the proposed HPLC method. Good agreement was found between the assay results and the label claim of the product. 
TABLE 4: Evaluation data of ruggedness study.

\begin{tabular}{|c|c|c|c|c|c|c|c|c|c|}
\hline \multirow{2}{*}{ Parameter } & \multicolumn{3}{|c|}{ EMT } & \multicolumn{3}{|c|}{ TDF } & \multicolumn{3}{|c|}{ RPV } \\
\hline & $(\mathrm{mg})$ & $(\%)$ & $\%$ RSD & $(\mathrm{mg})$ & $(\%)$ & $\%$ RSD & $(\mathrm{mg})$ & $(\%)$ & $\%$ RSD \\
\hline Analyst 1 & 200.11 & 100.05 & 0.64 & 300.12 & 100.04 & 0.112 & 25.06 & 100.24 & 0.132 \\
\hline Analyst 2 & 200.62 & 100.31 & 0.33 & 298.94 & 99.64 & 0.145 & 24.79 & 99.16 & 1.232 \\
\hline Instrument 1 & 200.18 & 100.09 & 0.634 & 300.29 & 100.09 & 0.146 & 24.81 & 99.26 & 0.246 \\
\hline Instrument 2 & 200.32 & 100.16 & 0.357 & 299.15 & 99.71 & 1.133 & 24.81 & 99.26 & 0.241 \\
\hline Lab 1 & 200.21 & 100.10 & 0.470 & 306.45 & 102.15 & 1.059 & 25.32 & 101.29 & 1.976 \\
\hline Lab 2 & 199.58 & 99.79 & 0.354 & 298.96 & 99.65 & 0.103 & 24.64 & 98.57 & 0.103 \\
\hline
\end{tabular}

TABLE 5: Evaluation data of solution stability study.

\begin{tabular}{|c|c|c|c|c|c|c|}
\hline \multirow{2}{*}{ Day } & EMT & TDF & RPV & EMT & TDF & RPV \\
\hline & \multicolumn{3}{|c|}{$\%$ assay for test preparation solution at $2-8^{\circ} \mathrm{C}$} & \multicolumn{3}{|c|}{$\%$ assay for test preparation solution at ambient temperature } \\
\hline Initial & 99.96 & 99.89 & 99.89 & 99.82 & 100.20 & 99.16 \\
\hline 1 & 99.89 & 99.75 & 99.84 & 99.82 & 100.92 & 99.17 \\
\hline 2 & 99.92 & 98.79 & 99.77 & 98.24 & 99.24 & 98.91 \\
\hline 3 & 98.45 & 98.59 & 99.56 & 98.45 & 99.09 & 98.44 \\
\hline
\end{tabular}

TABLE 6: Assay results for commercial formulation.

\begin{tabular}{|c|c|c|c|c|c|}
\hline Amount present (mg) & $(\%)$ & Amount present (mg) & $(\%)$ & Amount present (mg) & (\%) \\
\hline EMT & & TDF & & RPV & \\
\hline 198.21 & 99.10 & 300.48 & 100.16 & 24.92 & 99.70 \\
\hline 199.07 & 99.53 & 299.81 & 99.93 & 24.91 & 99.65 \\
\hline 198.21 & 99.10 & 296.63 & 98.87 & 24.63 & 98.54 \\
\hline 201.12 & 100.56 & 299.57 & 99.85 & 24.92 & 99.70 \\
\hline 200.55 & 100.27 & 298.91 & 99.63 & 24.94 & 99.77 \\
\hline 199.92 & 99.96 & 300.48 & 100.16 & 24.91 & 99.65 \\
\hline S.D & 0.579 & S.D & 0.494 & S.D & 0.523 \\
\hline$\%$ RSD & 0.579 & $\% \mathrm{RSD}$ & 0.495 & $\%$ RSD & 0.525 \\
\hline
\end{tabular}

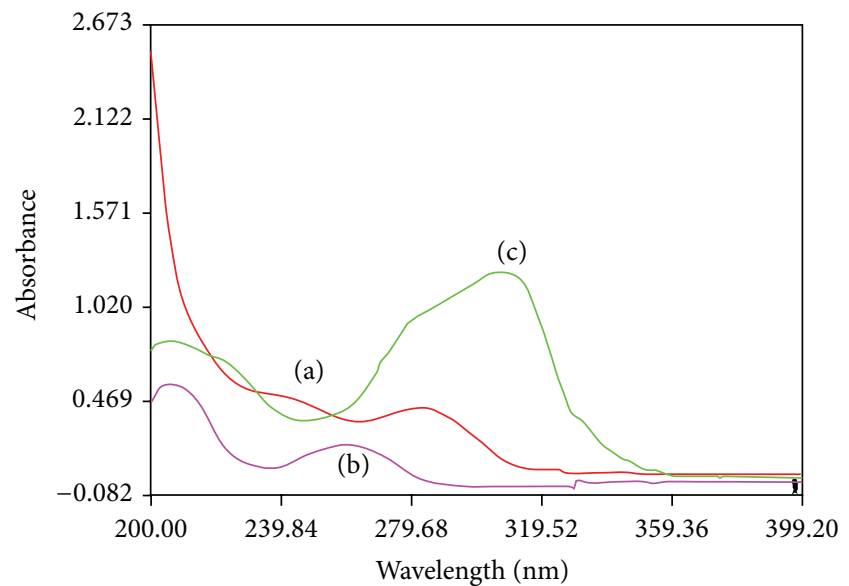

FIGURE 3: UV spectra of $10 \mu \mathrm{g} / \mathrm{mL}$ each of EMT, TDF, and RPV in methanol. (a) UV spectrum of EMT; (b) UV spectrum of TDF; (c) UV spectrum of RPV.

The $\%$ RSD for the tablets were $<2$, indicating the precision of the analytical methodology. The results are presented in Table 6.

\section{Conclusion}

An isocratic stability-indicating HPLC-UV method has been developed for the estimation of EMT, TDF, and RPV in the presence of degradation products. The proposed method is simple, accurate, precise, and specific and has the ability to separate the drugs from degradation products and excipients found in the pharmaceutical dosage forms. The method is suitable for use in routine analysis of both drugs in bulk API powder or in pharmaceutical dosage forms. The method can be applied even to the analysis of stability samples obtained during accelerated stability experiments, as no interference was found with the degradants formed under various stress conditions.

\section{Conflict of Interests}

Authors declared that they have no conflict of interests.

\section{Acknowledgment}

The authors are very much thankful to the Department of Pharmacy, Faculty of Engineering and Technology, Annamalai University. 


\section{References}

[1] "Q1AR2: stability testing of new drug substances, products IFPMA," in Proceedings of the International Conference on Harmonization (ICH '03), Geneva, Switzerland, 2003.

[2] H. B. Fung, E. A. Stone, and F. J. Piacenti, “Tenofovir disoproxil fumarate: a nucleotide reverse transcriptase inhibitor for the treatment of HIV infection," Clinical Therapeutics, vol. 24, no. 10, pp. 1515-1548, 2002.

[3] M. Sharma and L. D. Saravolatz, "Rilpivirine: a new nonnucleoside reverse transcriptase inhibitor," Journal of Antimicrobial Chemotherapy, vol. 68, no. 2, pp. 250-256, 2013.

[4] UNAIDS, AIDS Epidemic Update, WHO Regional Office Europe, 2009.

[5] S. Raffanti and D. Haas, Anti Microbial Agents: Anti-retroviral Agents, Mcgraw-Hill, New Yor, NY, USA, 2004.

[6] A. Rouzes, K. Berthoin, and F. Xuereb, "Simultaneous analysis antiretroviral drugs," Journal of Chromatography B, vol. 813, pp. 209-216, 2004.

[7] K. Anandakumar, K. Kannan, and T. Vetrichelvan, "Development and validation of emtricitabine and tenofovir Disoproxil fumerate in pure and in fixed dose combination by UV spectrophotometry," Digest Journal of Nanomaterials and Biostructures, vol. 6, no. 3, pp. 1085-1090, 2011.

[8] A. S. Atul, H. B. Charushila, and J. S. Sanjay, "Application of UVspectrophotometric methods for estimation of tenofovir disoproxil fumarate in tablets," Pakistan Journal of Pharmaceutical Sciences, vol. 22, no. 1, pp. 27-29, 2009.

[9] A. J. Pratap Reddy and I. E. Chakravarthy, "New spectrophotometric determination of tenofovir disoproxil fumaratein bulk and pharmaceutical dosage form," IOSR Journal of Applied Chemistry, vol. 1, no. 2, pp. 29-33, 2012.

[10] H. K. Ashour and T. S. Belal, "New simple spectrophotometric method for determination of the antiviral mixture of emtricitabine and tenofovir disoproxil fumarate," Arabian Journal of Chemistry, 2013.

[11] S. Patel, U. S. Baghel, P. Rajesh, D. Prabhakar, G. Engla, and P. N. Nagar, "Spectrophotometric method development Tenofovir disoproxil fumarate and Emtricitabine in Bulk drug and Tablet dosage form," International Journal of Pharmaceutical and Clinical Research, vol. 1, no. 1, pp. 28-30, 2009.

[12] P. B. Kandagal, D. H. Manjunatha, J. Seetharamappa, and S. S. Kalanur, "RP-HPLC method for the determination of tenofovir in pharmaceutical formulations and spiked human plasma," Analytical Letters, vol. 41, no. 4, pp. 561-570, 2008.

[13] M. E. Barkil, M.-C. Gagnieu, and J. Guitton, "Relevance of a combined UV and single mass spectrometry detection for the determination of tenofovir in human plasma by HPLC in therapeutic drug monitoring," Journal of Chromatography $B$, vol. 854, no. 1-2, pp. 192-197, 2007.

[14] V. Jullien, J.-M. Tréluyer, G. Pons, and E. Rey, "Determination of tenofovir in human plasma by high-performance liquid chromatography with spectrofluorimetric detection," Journal of Chromatography B, vol. 785, no. 2, pp. 377-381, 2003.

[15] R. W. Sparidans, K. M. L. Crommentuyn, J. H. M. Schellens, and J. H. Beijnen, "Liquid chromatographic assay for the antiviral nucleotide analogue tenofovir in plasma using derivatization with chloroacetaldehyde," Journal of Chromatography B, vol. 791, no. 1-2, pp. 227-233, 2003.

[16] M. Joshi, A. P. Nikalje, M. Shahed, and M. Dehghan, "HPTLC method for the simultaneous estimation of emtricitabine and tenofovir in tablet dosage form," Indian Journal of Pharmaceutical Sciences, vol. 71, no. 1, pp. 95-97, 2009.

[17] T. Delahunty, L. Bushman, and C. V. Fletcher, "Sensitive assay for determining plasma tenofovir concentrations by LC/MS/MS," Journal of Chromatography B, vol. 830, no. 1, pp. 6-12, 2006.

[18] B. Ahindita, P. Aurobinda, K. M. Amit, G. S. Dannana, K. M. Swapna, and C. S. I. Sudam, "Development and Validation of Spectrophotometric methods for determination of Emtricitabine and tenofovir disoproxil fumarate in Bulk and Tablet dosage Form," International Journal of PharmTech Research, vol. 3, no. 3, pp. 1874-1882, 2011.

[19] N. L. Rezk, R. D. Crutchley, and A. D. M. Kashuba, "Simultaneous quantification of emtricitabine and tenofovir in human plasma using high-performance liquid chromatography after solid phase extraction," Journal of Chromatography B: Analytical Technologies in the Biomedical and Life Sciences, vol. 822, no. 1-2, pp. 201-208, 2005.

[20] J. A. H. Droste, R. E. Aarnoutse, and D. M. Burger, "Determination of emtricitabine in human plasma using HPLC with fluorometric detection," Journal of Liquid Chromatography and Related Technologies, vol. 30, no. 18, pp. 2769-2778, 2007.

[21] D. Ashenafi, A. Verbeek, J. Hoogmartens, and E. Adams, "Development and validation of an LC method for the determination of emtricitabine and related compounds in the drug substance," Journal of Separation Science, vol. 32, no. 11, pp. 18231830, 2009.

[22] N. A. Gomes, V. V. Vaidya, A. Pudage, S. S. Joshi, and S. A. Parekh, "Liquid chromatography-tandem mass spectrometry (LC-MS/MS) method for simultaneous determination of tenofovir and emtricitabine in human plasma and its application to a bioequivalence study," Journal of Pharmaceutical and Biomedical Analysis, vol. 48, no. 3, pp. 918-926, 2008.

[23] U. Seshachalam, B. Haribabu, and K. B. Chandrasekhar, "Development and validation of a stability-indicating liquid chromatographic method for determination of emtricitabine and related impurities in drug substance," Journal of Separation Science, vol. 30, no. 7, pp. 999-1004, 2007.

[24] G. B. Bhavar, S. S. Pekamwar, K. B. Aher, and S. R. Chaudhari, "Development and validation of UV Spectrophotometric method for estimation of rilpivirine hydrochloride in bulk and pharmaceutical formulations," American Journal of PharmTech Research, vol. 3, no. 1, pp. 450-458, 2013.

[25] G. Somsubhra, B. Sowjanya, P.V. Laxmi, S. Vidyadhar, B. David, and R. Subhadip, "Method development and validation of rilpivirine in bulk and tablet doses form by RP-HPLC method," Research Journal of Pharmacy and Technology, vol. 6, no. 3, pp. 240-243, 2013.

[26] T. Sudha and P. Shanmugasundram, "Reverse phase high performance and HPTLC methods for the determination of rilpivirine bulk and in tablet dosage form," World Journal of Pharmaceutical Research, vol. 1, no. 4, pp. 1183-1196, 2012.

[27] K. Y. Kavitha, G. Geetha, R. Hariprasad, R. Venkatnarayanan, and M. Kaviarasu, "Development and validation of RP-UPLC analytical method for simultaneous estimation of the emtricitabine, tenofovir disoproxil fumerate and rilpivirine and its pharmaceutical dosageform," International Research Journal of Pharmacy, vol. 4, no. 1, pp. 150-155, 2013.

[28] D. Pranitha, C. Vanitha, P. Francies et al., "Simultaneous estimation of Emtricitabine, Tenofovir disoproxil fumarate and Rilpivirine in bulk form by RP-HPLC method," Journal of Pharmacy Research, vol. 5, no. 8, pp. 4600-4602, 2012. 
[29] D. N. Reynolds, K. L. Facchine, J. F. Mullaney, K. M. Alsante, T. D. Hatajik, and M. G. Motto, "Available guidance and best practices for conducting forced degradation studies," Pharmaceutical Technology, vol. 26, no. 2, pp. 48-56, 2002.

[30] S. Singh and M. Bakshi, "Guidance on conduct of stress tests to determine inherent stability of drugs," Pharmatech, vol. 24, pp. $1-14,2000$.

[31] ICH Q2( R1) Guideline, Validation of Analytical Procedures: Text and Methodology, ICH, Geneva, Switzerland, 2005. 

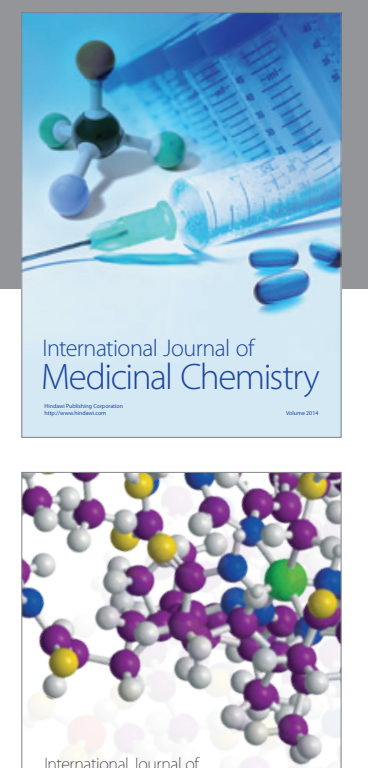

\section{Carbohydrate} Chemistry

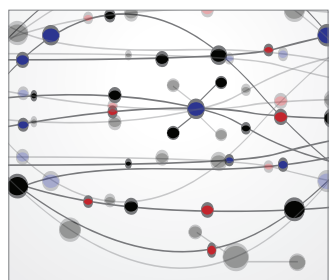

The Scientific World Journal
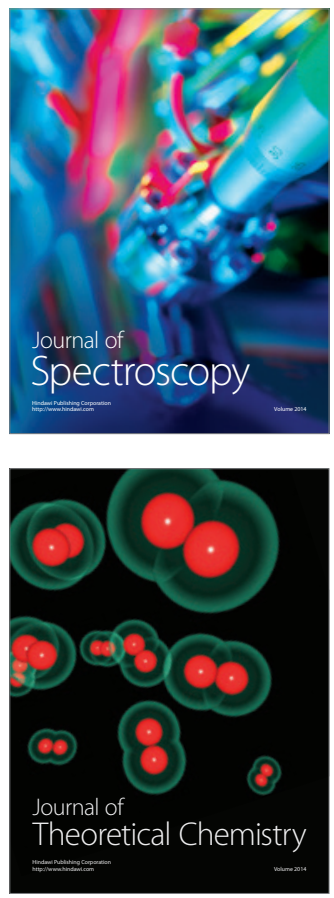
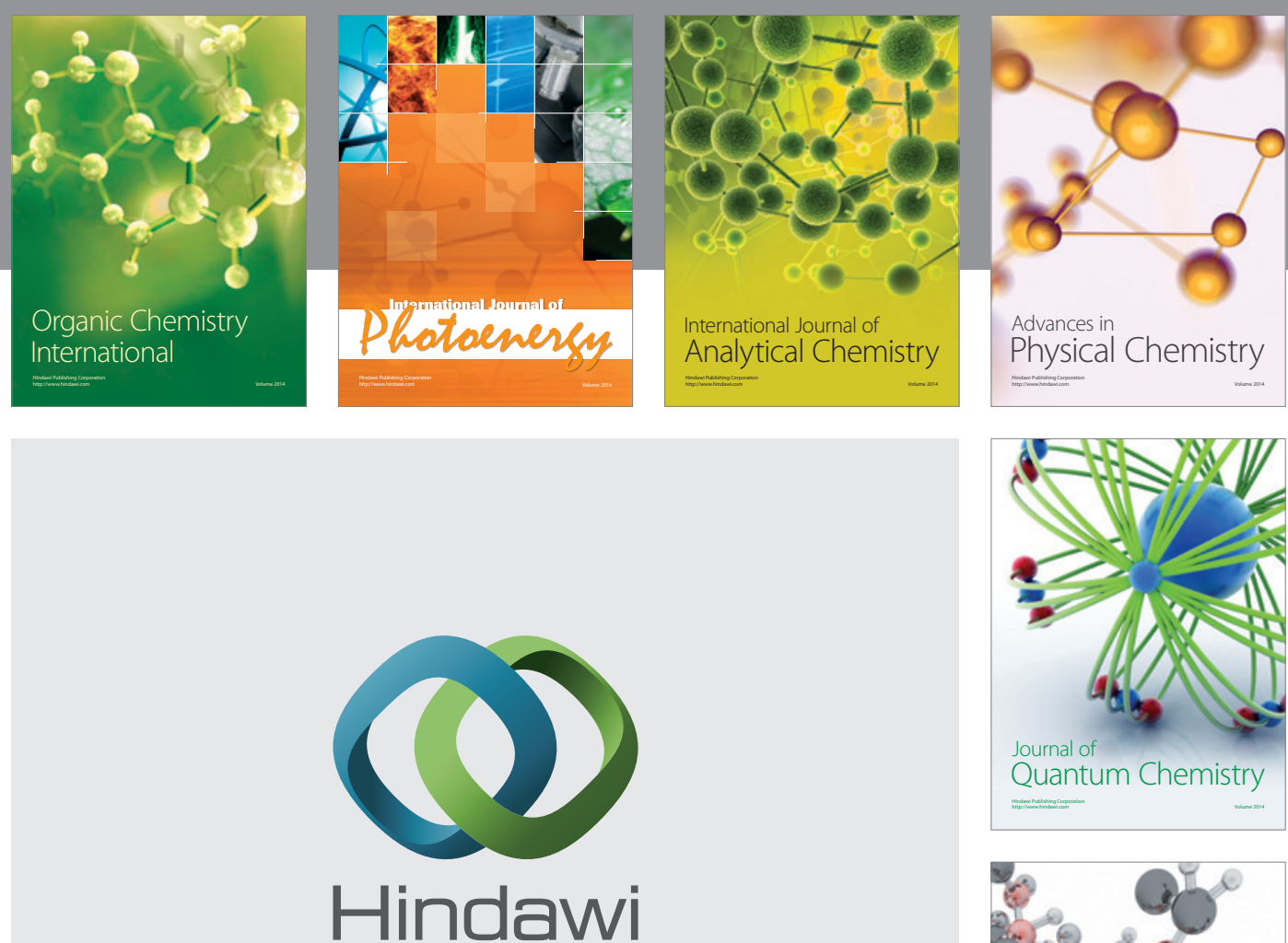

Submit your manuscripts at

http://www.hindawi.com

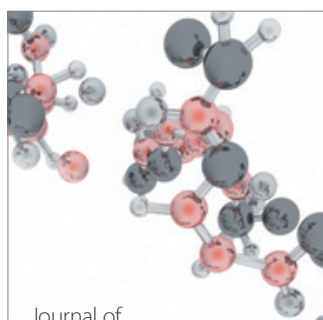

Analytical Methods

in Chemistry

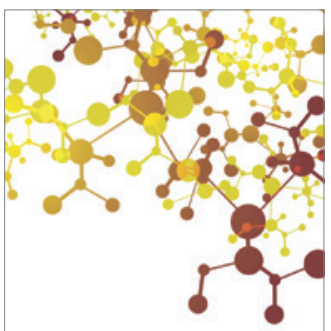

Journal of

Applied Chemistry

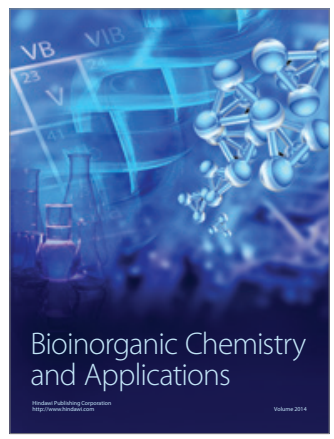

Inorganic Chemistry
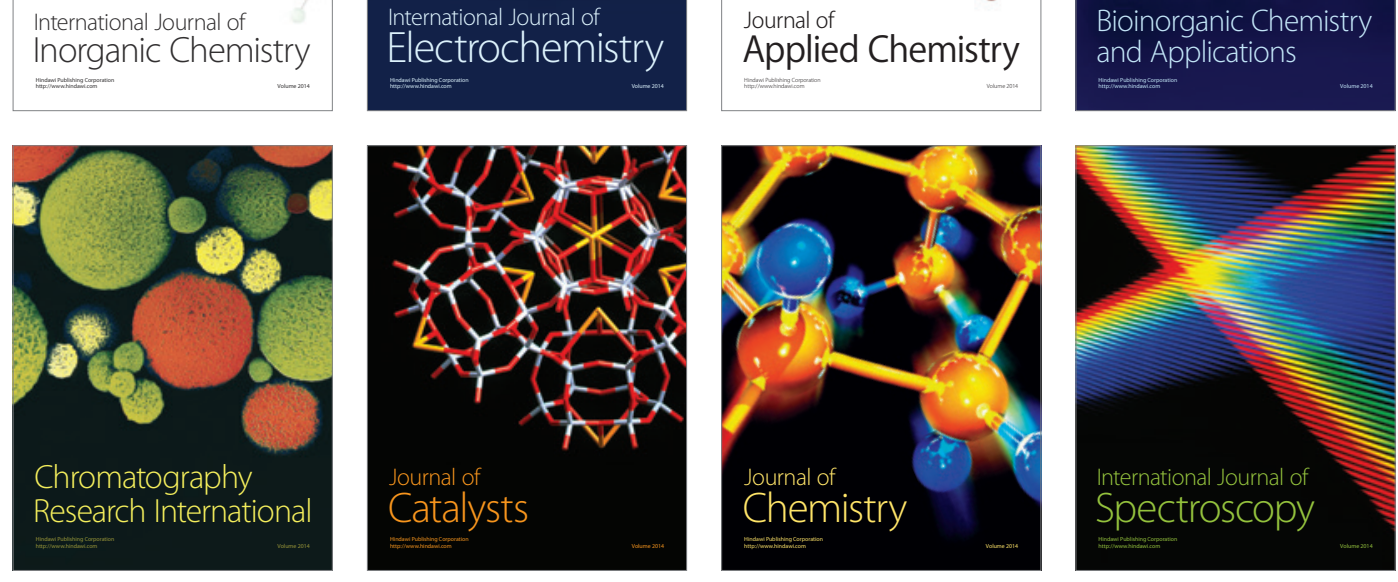